\title{
Inquérito Malacológico em Localidades Endêmicas para Esquistossomose em Pernambuco, Brasil
}

\author{
Malacological Survey in Endemic Locations for Schistosomiasis in Pernambuco, Brazil \\ Estudio malacológico sobre lugares endémicos para la esquistosomiasis in Pernambuco, \\ Brasil
}

Constança Simões Barbosa ${ }^{1}$, Rodrigo Moraes Loyo ${ }^{1}$, Wheverton Ricardo Correia do Nascimento ${ }^{1,2 *}$, Elainne Christine de Souza Gomes ${ }^{1}$, Bárbara Morgana da Silva ${ }^{3}$, Gleice Maria dos Santos ${ }^{3}$ e José Alexandre Menezes da Silva ${ }^{3}$.

\section{RESUMO}

Objetivo: Realizar inquérito malacológico para detectar a presença do Schistosoma mansoni (SM) em caramujos Biomphalaria em locais com e sem ações do SANAR para verificar a circulação ambiental do parasita. Métodos: As coletas ocorreram entre 2017 e 2018 em 61 localidades com intervenção SANAR e em 60 localidades contiguas, sem SANAR. Os exemplares de B. glabrata (BG) e B. straminea (BS) coletados foram examinados pela técnica de exposição à luz e esmagamento para identificação de formas larvais do SM. Os BS negativos foram examinados também pela Nested PCR para detecção de DNA do parasita. Resultados: Foram coletados 5.459 moluscos nesse estudo. Nas 61 localidades com atuação SANAR foram coletados 204 BG e 2.056 BS, com 10 locais (16,4\%) apresentando caramujos positivos para infecção pelo SM contra 51 locais $(83,6 \%)$ com caramujos sadios. Nas 60 localidades sem intervenção SANAR foram coletados 19 BG e 3.180 BS, onde 33 locais (55\%) com caramujos positivos para SM e 27 locais (45\%) com caramujos sadios. Conclusão: A presença do DNA do SM em moluscos de localidades onde o SANAR não medicou as pessoas garante que o parasito circula localmente, representando risco biológico e alerta para o início do ciclo de transmissão da parasitose.

Palavras-Chave: Esquistossomose mansoni, Biomphalaria, Doenças Endêmicas, Praziquantel.

\begin{abstract}
Objective: To carry out a malacological survey to detect the presence of Schistosoma mansoni (SM) infection in Biomphalaria snails in localities with and without SANAR in order to verify the environmental circulation of SM. Methods: The survey occurred between 2017 and 2018 in 61 localities with SANAR actions and in 60 contiguous localities without SANAR. The B. glabrata (BG) and B. straminea (BS) specimens collected were examined by light exposure and crushing technique to identify larval forms of SM. Negative specimens of BS were also examined by Nested PCR technique to detect the parasite DNA. Results: A total of 5,459 snails were collected. In the 61 localities with SANAR, 204 BG and 2,056 BS were collected, with 10 sites (16.4\%) presenting positive snails for SM infection against 51 sites (83.6\%) with healthy snails. In the 60 localities without SANAR, 19 BG and 3,180 BS were collected, with 33 sites (55\%) having positive snails for SM and 27
\end{abstract}

\footnotetext{
1 Instituto Aggeu Magalhães (IAM) / Fiocruz-PE, Departamento de Parasitologia, Laboratório de Referência em Esquistossomose, Recife-PE. *E-mail: wheverton.nascimento@gmail.com

2 Universidade Federal de Pernambuco (UFPE), Centro de Ciências Médicas, Área acadêmica de Medicina Tropical, Recife-PE.

${ }^{3}$ Secretaria de Saúde do Estado de Pernambuco (SES-PE), Programa de Controle da Esquistossomose, Recife-PE.
} 
sites $(45 \%)$ with healthy snails. Conclusion: The presence of SM DNA in snails from localities where the SANAR didn't medicate people, guarantees the parasite circulation locally which represents biological risk and alert to the beginning of the parasitic transmission.

Key words: Schistosomiasis mansoni, Biomphalaria, Endemic Diseases, Praziquantel.

\section{RESUMEN}

Objetivo: Realizar una investigación malaquológica para detectar la presencia de Schistosoma mansoni (SM) en caracoles Biomphalaria en lugares con y sin acciones SANAR para verificar la circulación ambiental del parásito. Métodos: la recolección de datos se realizó entre 2017 y 2018 en 61 localidades con intervención de SANAR y en 60 localidades contiguas, sin SANAR. Las muestras de B. glabrata (BG) y B. straminea (BS) recogidas se examinaron mediante la exposición a la luz y la técnica de trituración para identificar las formas larvarias de SM. Las BS negativas también se examinaron mediante PCR anidada para la detección del ADN del parásito. Resultados: se recolectaron 5,459 moluscos en este estudio. En las 61 localidades con rendimiento SANAR, se recolectaron 204 BG y 2,056 BS, con 10 sitios (16.4\%) que presentaron caracoles positivos para la infección por SM contra 51 sitios (83.6\%) con caracoles sanos. En las 60 localidades sin intervención de SANAR, se recolectaron 19 BG y 3,180 BS, con 33 sitios (55\%) con caracoles SM positivos y 27 sitios (45\%) con caracoles sanos. Conclusión: La presencia de ADN de SM en moluscos de localidades donde SANAR no medicó a las personas garantiza que el parásito circula localmente, lo que representa un riesgo biológico y alerta al comienzo del ciclo de transmisión del parásito.

Palabras clave: Esquistosomiasis mansoni, Biomphalaria, Enfermedades Endémicas, Praziquantel.

\section{INTRODUÇÃO}

A esquistossomose mansônica é uma doença de importante impacto na saúde pública no Brasil, ocorrendo de forma endêmica em 19 unidades federativas desde o Maranhão até o Espírito Santo e Minas Gerais, e em pequenos focos em outros estados do país. As prevalências mais elevadas são encontradas em Alagoas, Pernambuco, Sergipe, Minas Gerais, Bahia e Paraíba (KATZ N, 2018).

Dentre os 185 municípios do estado de Pernambuco a esquistossomose é endêmica em 101 (54,6\%), a maioria deles situados nas regiões da Zona da Mata e Metropolitana do Recife (BARRETO AVMS, et al., 2015; SAUCHA CVV, et al. 2015) com inúmeros focos de transmissão ativa registrados em localidades turísticas do litoral deste Estado (BARRETO MS, et al., 2016; BARBOSA CS, et al., 2015; BARBOSA CS, et al., 2018). Os dados sobre a doença em Pernambuco são expressivos: entre 1999 a 2013 foram registrados 2.578 óbitos - maior taxa de mortalidade do Nordeste do País - e entre 2008 a 2014 ocorreram 473 internações hospitalares com $72,6 \%$ de indivíduos apresentando a forma clínica grave da doença (BARBOSA CS, et al., 2016). Essas informações, quando comparadas a outros estados do Brasil, apontam para a elevada magnitude da endemia em Pernambuco.

Diante deste cenário epidemiológico, a Secretaria Estadual de Saúde de Pernambuco iniciou em 2011 o Programa SANAR (Programa de Enfrentamento às Doenças Negligenciadas) como estratégia de governo pautada em agenda internacional (ORGANIZAÇÃO PANAMERICANA DA SAÚDE, 2009) visando eliminar ou reduzir a transmissão de doenças transmissíveis negligenciadas (DTN) entre elas a esquistossomose.

Para as ações do SANAR, foram selecionados municípios endêmicos entre os anos de 2005 a 2010 de acordo com a base estadual do sistema de informação do programa de controle da esquistossomose (PERNAMBUCO, 2013). Como estratégia para o controle da esquistossomose, o tratamento seletivo (TS) foi realizado em localidades com positividade inferior a 10\% e o tratamento coletivo (TC) quando a positividade era igual ou superior a $10 \%$, envolvendo as atividades de vigilância, diagnóstico e tratamento dos casos positivos de forma integrada com as equipes da Estratégia de Saúde da Família-ESF (PERNAMBUCO, 2012). 
As ações de TC e TS nas localidades prioritárias para o SANAR, foram realizados no período 2011 a 2014 e os inquéritos malacológicos, objeto do presente artigo, foi realizado entre 2017 a 2018.

Em $90 \%$ dos municípios endêmicos para esquistossomose no estado de Pernambuco, o caramujo responsável pela transmissão da doença é o $B$. straminea considerado um mau vetor biológico tendo em vista sua rápida mortalidade após infecção pelo $S$. mansoni em condições de laboratório. A refratariedade desta espécie na eliminação das cercárias é atribuída ao seu sistema imunológico e à ativação de genes de resistência (CAVALCANTI MGS, et al., 2012). Por este motivo, nos inquéritos malacológicos tem-se utilizado a técnica de diagnóstico molecular NESTED PCR (ABATH FGC, et al., 2006) para detectar a presença do DNA do $S$. mansoni em moluscos $B$. straminea. Os ensaios de PCR para este tipo de diagnóstico se justificam pela precisão, especificidade e rapidez na detecção do DNA do parasito no Biomphalaria e vêm sendo utilizado em caramujos vetores que se mostram negativos à infecção pelo parasita no teste clássico de exposição à luz (KUNTZ R, 1946).

Diante do exposto, o presente estudo teve como objetivo realizar inquérito malacológico para detectar a presença de infecção pelo S. mansoni nos caramujos do gênero Biomphalaria nas localidades com e sem ações medicamentosas do Programa SANAR, após 3 anos de atuação do mesmo, com o intuito de verificar a circulação do parasita nessas áreas.

\section{MÉTODOS}

Para a realização do inquérito malacológico foram selecionadas aleatoriamente 61 localidades onde as populações humanas foram submetidas a qualquer tipo de estratégia medicamentosa pelo SANAR (Ioc com SANAR) e 60 outras localidades contiguas na mesma região geográfica e no mesmo período onde não foi realizado nenhum tipo de intervenção (Ioc sem SANAR). Todas as localidades do estudo se situam em municípios pertencentes a área endêmica para esquistossomose em Pernambuco.

As coletas dos caramujos foram realizadas numa parceria entre o Laboratório de Referência em Esquistossomose (LRE) do Instituto Aggeu Magalhães (IAM) - Fiocruz/PE e a equipe de Malacologia do Programa SANAR entre outubro de 2017 a outubro de 2018. Os moluscos foram coletados em todos os criadouros existentes nas localidades, por pesquisa sistemática na extensão da coleção hídrica com 1 hora de coleta em cada uma. O esforço de coleta foi duplicado nos pontos de importância epidemiológica de cada criadouro: proximidade das residências e/ou locais de afluxo humano. De cada lote de moluscos coletados eram retirados $10 \%$ de exemplares para identificação da espécie através de dissecção do aparelho genital (DESLANDES N, 1951). Em seguida os caramujos eram examinados para verificação da infecção pelo $S$. mansoni por meio das técnicas (I) exposição à luz para verificação da eliminação de cercárias do parasita (SOUZA CP e LIMA LC, 1990); (II) esmagamento para identificação de formas larvais do parasita (BRASIL, 2008) e (III) Reação em cadeia da polimerase (PCR) do tipo NESTED para detecção de DNA do parasita nos caramujos (ABATH FGC, et al., 2006). Os exemplares de B. glabrata foram examinados pela técnica de exposição à luz e esmagamento e os $B$. straminea que não se mostraram positivos na exposição à luz foram encaminhados para a PCR.

Após o resultado dos exames para detecção da infecção pelo S. mansoni nos exemplares de Biomphalaria $\mathrm{sp}$. os locais de coleta de caramujo foram classificados da seguinte forma: Criadouro = locais onde os caramujos se apresentaram sadios; Foco em Potencial = onde foi identificado o DNA do S. mansoni por meio da PCR. Foco = locais onde os caramujos eliminaram cercárias pela técnica de exposição à luz.

Os criadouros foram georreferenciados com um receptor GPS (Global Positioning System) Garmin, modelo Montana 680, configurado no sistema de projeção UTM (Universal Transversa de Mercator), Datum SIRGAS 2000. O mapeamento mostrou precisão abaixo de 10 metros (erro < 10 menos). Em um Sistema de Informação Geográfica (SIG) foram compilados e analisados os dados coletados, no qual foram gerados mapas temáticos com atributos para a espécie e densidade de caramujos para projetar pontos de risco para a exposição humana a infecção pelo $S$. mansoni. O risco foi determinado pelo estimador de Kernel, gerando mapas com gradiente cromático. Como produto desse tipo de análise foi possível evidenciar as "zonas 
quentes" que mostram a densidade de caramujos aglomerados em pontos que representam locais com risco para transmissão da esquistossomose (BAILEY TC e GATRELL AC, 1995). A Interpolação pela Ponderação do Inverso da Distância (IDW) foi utilizada para gerar uma superfície contínua com os dados de saneamento básico de cada município (HARMAN BI, et al., 2016). As informações de saneamento foram disponibilizadas pelo Instituto Brasileiro de Geografia e Estatística (IBGE, 2010).

\section{RESULTADOS}

No período da pesquisa foram coletados 5.459 exemplares de caramujos do gênero Biomphalaria nas localidades do estudo: 2.056 B. straminea e 204 B. glabrata nas 61 loc com SANAR e 3.180 B. straminea e 19 B. glabrata nas 60 loc sem SANAR.

Observou-se uma taxa de positividade para o $S$. mansoni menor nas loc com SANAR em relação as sem SANAR, sendo 16,4\% (10/61) para loc com SANAR e 45\% (27/60) para as sem SANAR. A espécie de molusco hospedeiro intermediário do S. mansoni que predominou foi o B. straminea, sendo identificados em $90,2 \%$ das localidades com intervenção SANAR e $98,3 \%$ das localidades sem intervenção SANAR. Conforme mostra a Figura 1, o B. glabrata foi encontrado em apenas 6 localidades com atuação do SANAR e 1 localidade sem atuação do SANAR. Somente nas localidades de Salinas e Sotave, em Porto de Galinhas (Ipojuca), e Lagoa das Garças, em Jaboatão dos Guararapes é que foram diagnosticados B. glabrata eliminando cercárias de S. mansoni, as demais localidades positivas foram identificadas apenas pela técnica de NESTED PCR utilizada nos espécimes de B. straminea.

Figura 1 - Localidades de estudo com as espécies de Biomphalaria encontradas.

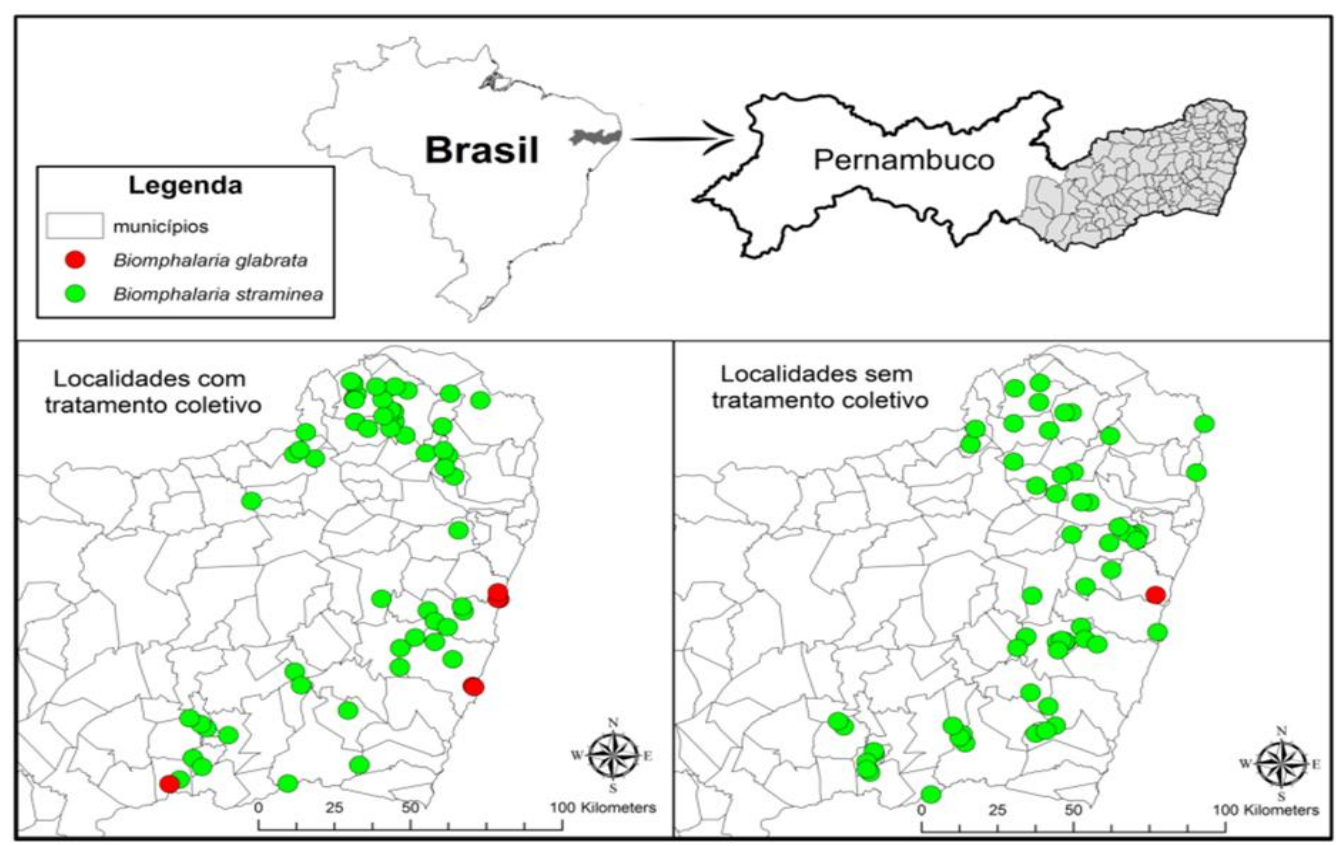

Fonte: Os Autores, 2019.

A análise de distribuição espacial dos pontos de coleta de caramujos pode ser visualizada na Figura 2 , onde se evidencia maior presença e distribuição de criadouros com caramujos sadios nas localidades com intervenção do SANAR, e um maior quantitativo e dispersão de Focos em Potencial (caramujos diagnosticados com DNA do parasita) nas localidades onde o SANAR não atuou. Os resultados apresentados na Gráfico 1 ratificam os achados da Figura 2 e demonstram que a porcentagem de caramujos sadios e infectados em locais sem a intervenção SANAR é bem próxima, ao contrário dos locais com tratamento do SANAR onde a proporção entre os moluscos sadios e infectados é bem divergente. 
Figura 2 - Presença de caramujos Biomphalaria positivos e negativos para a infecção pelo $S$. mansoni nas localidades do estudo, com (A) e sem (B) intervenção do SANAR.

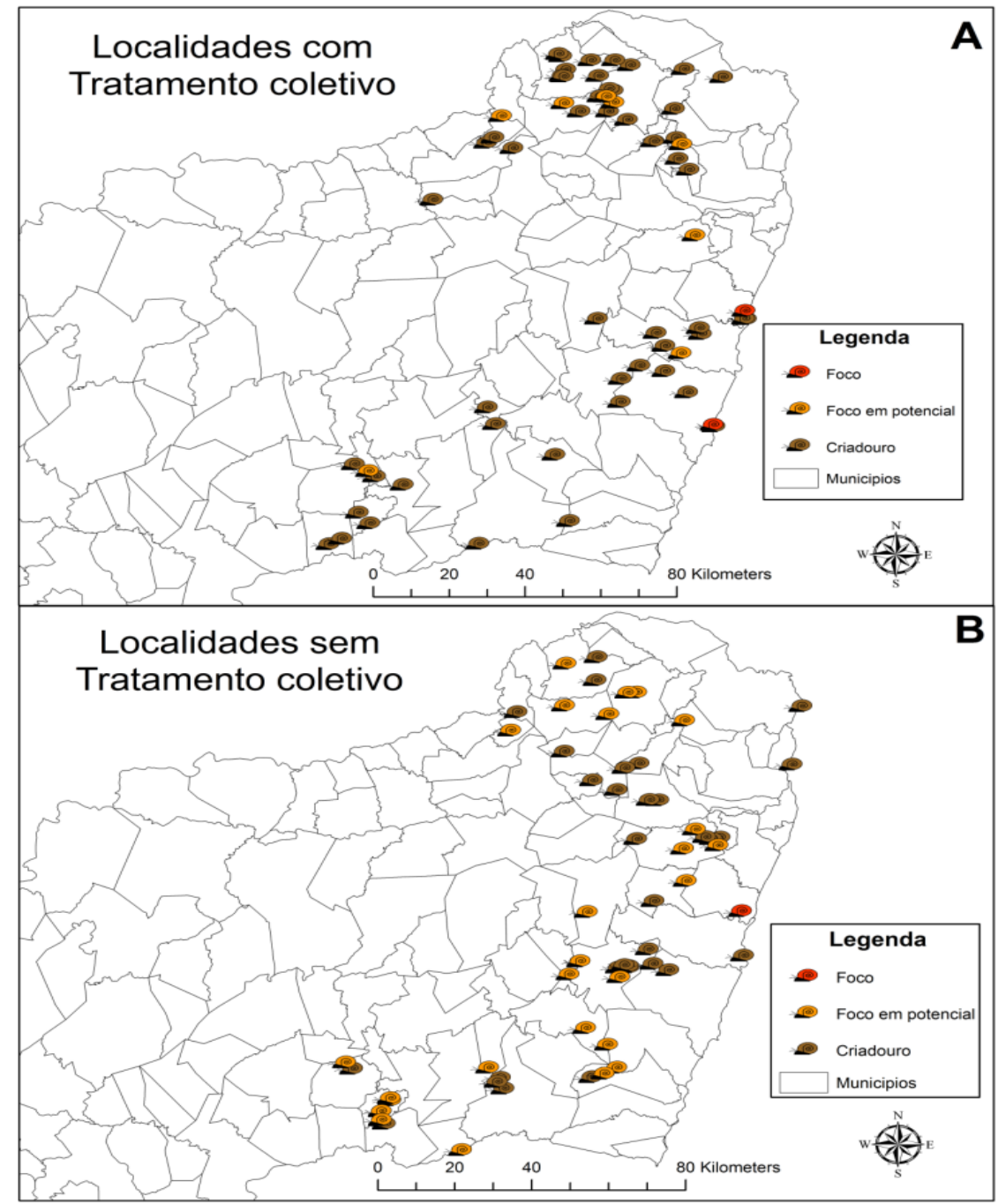

Fonte: Os Autores, 2019.

Gráfico 1 - Resultado das análises de positividade para infecção pelo S. mansoni nos caramujos das localidades de estudo.

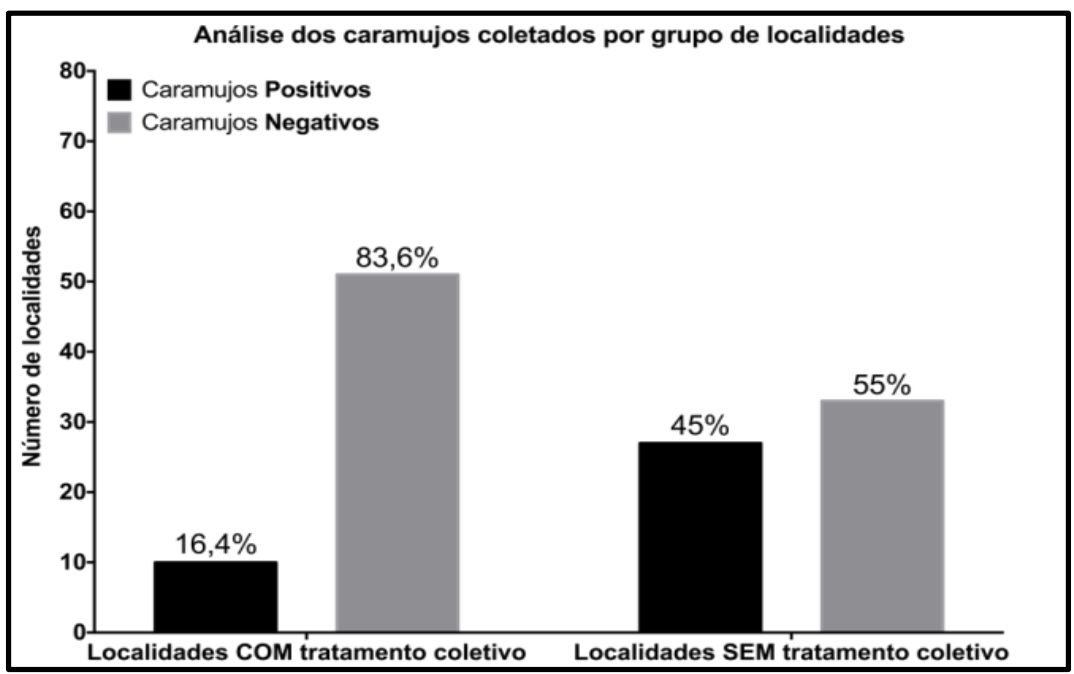

Fonte: Os Autores, 2019. 
As "áreas quentes" construídas pelo estimador Kernel (Figura 3A e B), demostram que o aglomerado dos caramujos infectados pelo $S$. mansoni foi menor nas áreas com atuação do SANAR (Figura 3A) em comparação com os locais sem intervenção do SANAR (Figura 3B). Ainda nesta figura, na posição lestenordeste do mapa, situada na Região Metropolitana do Recife, percebe-se a presença de uma "área quente" em congruência entre as localidades com e sem SANAR. Com relação aos dados da Figura $\mathbf{3 C}$, vimos que na área acima mencionada o saneamento é inadequado segundo dados do IBGE (IBGE, 2010). O fato desta região ter o saneamento precário pode facilmente ser associado ao indicativo de área de risco em ambas localidades como mostrado na Figura 3A e B.

Figura 3 - Concentração de caramujos positivos para infecção pelo S. mansoni nas localidades com (A) e sem (B) intervenção do programa SANAR; (C) distribuição dos focos, focos em potencial e criadouros de Biomphalaria sp., nas localidades com e sem atuação do SANAR, em relação ao nível de saneamento dos municípios de Pernambuco.

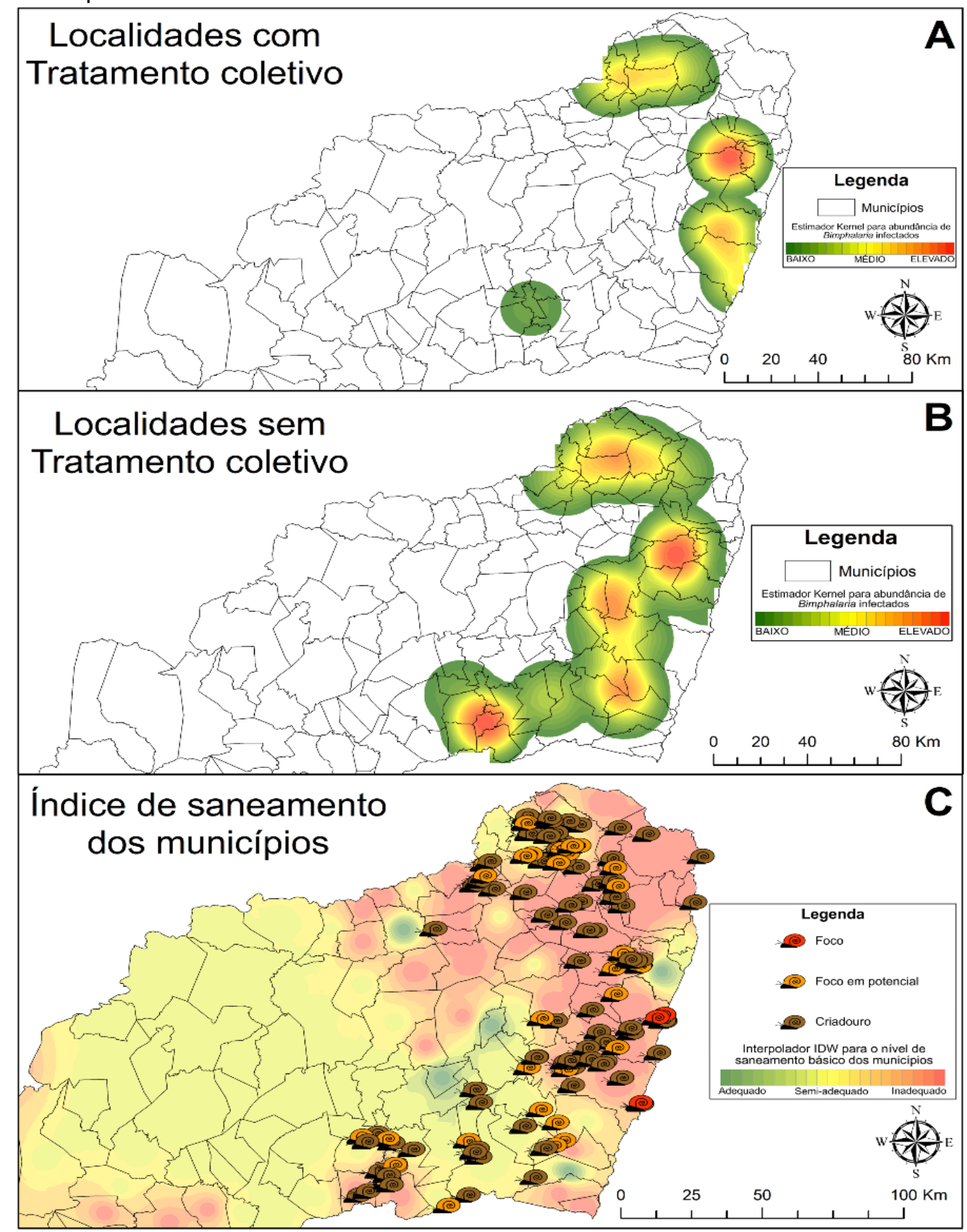

Fonte: Os Autores, 2019. 


\section{DISCUSSÃO}

Entre as localidades do estudo, situadas na área endêmica para esquistossomose, $94,2 \%$ delas apresentaram o caramujo vetor $B$. straminea que, mesmo sendo um mau vetor do ponto de vista biológico, consegue manter estáveis as taxas de prevalências para a doença (MORGAN JAT, et al., 2002; BARBOSA CS, et al., 2010). A figura 1 mostra a distribuição geográfica das espécies de vetores na região de transmissão da esquistossomose, destacando-se a significativa presença de criadouros de $B$. straminea em contraste com poucos criadouros de $B$. glabrata que ocorrem somente em algumas localidades litorâneas. Apesar de se apresentar com número bem menor de criadouros, os focos litorâneos de $B$. glabrata têm sido responsáveis por surtos e casos agudos de esquistossomose devido à excelente qualidade de vetor desta espécie, que sustenta bem a infecção e é capaz de eliminar um expressivo número de larvas infectantes (DIAS LC, et al., 1987; FAVRE TC, et al., 2002). O presente estudo salienta a manutenção dos focos de B. glabrata nas localidades Porto de Galinhas (Ipojuca) e Lagoa das Garças (Jaboatão) identificados e mapeados há anos por uma Expedição Cientifica realizada no litoral de Pernambuco (BARBOSA CS, et al., 2015) Com relação aos achados do exame dos hospedeiros através da técnica de diagnóstico molecular NESTED PCR para identificar o DNA do S. mansoni e da técnica clássica de exposição a luz para visualização da eliminação das cercárias, a positividade dos lotes de caramujos foi de $16,4 \%$ nas loc com SANAR e de $45 \%$ nas loc sem SANAR o que aponta maior circulação dos parasitas nos criadouros das localidades onde o Programa SANAR não atuou (Gráfico 1). Esta informação pode ser melhor visualizada na figura 2 que destaca a localização georreferenciada das localidades do estudo - com e sem intervenção do SANAR - mostrando localmente a presença de caramujos Biomphalaria positivos e negativos para o DNA do S. mansoni.

Sabe-se que a presença do DNA do $S$. mansoni não é condição suficiente para se afirmar que o caramujo desenvolveu o ciclo deste parasito ou que está havendo transmissão da esquistossomose. O parasito pode penetrar no molusco hospedeiro e não evoluir para outras fases do seu desenvolvimento devido às barreiras imunológicas inerentes ao caramujo vetor (YOSHINO TP, et al., 2013; ALLAN ERO, et al., 2017). Do ponto de vista epidemiológico também não podemos afirmar que a presença do DNA do Schistosoma no hospedeiro intermediário é evidencia de transmissão focal da doença uma vez que existe a possibilidade de não estar havendo eliminação de cercárias do parasito. Contudo, em localidades onde a transmissão da doença não está patente, a presença do DNA do S. mansoni em moluscos do gênero Biomphalaria garante que o parasito está circulando localmente nos criadouros dos caramujos, o que representa risco biológico e alerta para o início do ciclo de transmissão da parasitose.

A figura 3 A e B trazem um subsídio relevante para o planejamento estratégico de ações do Programa de Controle da Esquistossomose no estado de Pernambuco no que diz respeito a concentração de criadouros onde os caramujos se apresentaram positivos para a infecção pelo $S$. mansoni em determinadas localidades deste Estado. No mapa observam-se as "zonas quentes" que representam a densidade desses caramujos e os locais de risco (aglomerados) para exposição humana. Mapas temáticos deste tipo vêm sendo disponibilizado na literatura como instrumento epidemiológico de diagnóstico ambiental de risco (BARBOSA VS, et al., 2016; BARBOSA VS, et al., 2017).

O mapa de interpolação dos níveis de saneamento (figura $3 \mathbf{C}$ ) aponta a associação entre a precariedade de saneamento básico e aglomerados de caramujos. Em relação a agravos como a esquistossomose, 0 destino inadequado dos dejetos humanos e a ausência de gestão sanitária do meio ambiente promovem ambientes insalubres mantendo a transmissão da doença.

Os resultados desta pesquisa sugerem a eficácia (temporária) das ações de controle da esquistossomose pelo Programa SANAR em Pernambuco, no sentido de que o tratamento nas populações humanas promove não somente o benefício da cura no indivíduo parasitado mas parece também ter impacto na epidemiologia e transmissão da esquistossomose ao minimizar a circulação do parasita nos ambientes aquáticos (criadouros dos moluscos vetores) frequentados pelas populações de localidades endêmicas.

Outros resultados referentes às ações do Programa SANAR foram observados por Facchini LA et al. (2018) através de um estudo transversal em 117 localidades hiperendêmicas trabalhadas pelo Programa no

REAS/EJCH | Vol.11(14) | e1235 | DOI: https://doi.org/10.25248/reas.e1235.2019 Página 7 de 9 
período de 2011 a 2014, que comparou a prevalência da esquistossomose nas populações locais antes e depois da intervenção do SANAR, mostrando uma redução na prevalência média de esquistossomose de $18,6 \%$ para $4,1 \%$ e $2,0 \%$ em 3 anos, em locais com um e dois ciclos de tratamento. Essa análise ajustada também mostrou uma menor ocorrência de esquistossomose em indivíduos que vivem em áreas com dois ciclos de tratamento do que em indivíduos de áreas com apenas um ciclo.

Apesar destes resultados, deve-se levar em consideração que, após o tratamento coletivo, os residentes de localidades endêmicas estão susceptíveis à reinfecção uma vez que continuam expostos aos mesmos ambientes insalubres, como evidenciado na figura 3C. Estudos do SANAR, realizados nas localidades trabalhadas pelo Programa, mostraram que não foi realizado qualquer tipo de saneamento ou tratamento dos dejetos humanos nestes locais ${ }^{3}$. Aliado a isto, deve-se levar em consideração o resíduo de pessoas que não puderam ser medicadas, ocorrência rotineira e previsível em programas de tratamento coletivo ou seletivo. Apesar de pequeno, este contingente populacional de casos positivos continuará promovendo a contaminação fecal do meio ambiente, podendo restabelecer a transmissão da parasitose em médio prazo.

\section{CONCLUSÃO}

O controle efetivo de doenças de veiculação hídrica, como a esquistossomose, exige abordagem integrada dos setores da saúde, educação e do meio ambiente que possam implementar intervenções duradouras na infraestrutura sanitária das localidades de áreas endêmicas, instrumentalizando e mobilizando as comunidades com informação para a saúde no sentido de promover melhoria na qualidade das suas vidas e no seu meio ambiente.

\section{AGRADECIMENTOS E FINANCIAMENTO}

Agradecemos aos técnicos do Laboratório de Referência em Esquistossomose do Instituto Aggeu Magalhães e aos técnicos do Programa de Controle da Esquistossomose do Estado de Pernambuco por toda a ajuda na extensa coleta das amostras desse estudo e no pré-processamento das mesmas.

\section{REFERÊNCIAS}

1. KATZ N. Inquérito Nacional de Prevalência da Esquistossomose mansoni e Geo-helmintoses. Belo Horizonte: Instituto René Rachou; 2018. 76 p.

2. BARRETO AVMS, et al. Análise da positividade da esquistossomose mansoni em Regionais de Saúde endêmicas em Pernambuco, 2005 a 2010. Epidemiol e Serviços Saúde [Internet]. 2015; 24(1): 87-96.

3. SAUCHA CVV, et al. Condições de saneamento básico em áreas hiperendêmicas para esquistossomose no estado de Pernambuco em 2012. Epidemiol e Serviços Saúde [Internet]. 2015; 24(3): 497-506.

4. BARRETO MS, et al. Turismo de risco em áreas vulneráveis para a transmissão da esquistossomose mansônica no Brasil. Cad Saude Publica. 2016; 32(3): 1-3.

5. BARBOSA CS, et al. Turismo de risco para esquistossomose mansônica em Porto de Galinhas, Estado de Pernambuco, Brasil. Rev Pan-Amazônica Saúde [Internet]. 2015; 6(3): 51-8.

6. BARBOSA CS, et al. Insalubrious touristic environments and schistosomiasis transmission in Pernambuco, Brazil. Rev Ambient e Agua. 2018; 13(3) e2151.

7. BARBOSA CS, et al. Morbidity of mansoni schistosomiasis in Pernambuco-Brazil: Analysis on the temporal evolution of deaths, hospital admissions and severe clinical forms (1999-2014). Acta Trop. 2016; 164: 10-6.

8. ORGANIZAÇÃO PANAMERICANA DA SAÚDE - OPAS. ELIMINAÇÃO DE DOENÇAS NEGLIGENCIADAS E OUTRAS INFECÇÕES RELACIONADAS À POBREZA. Washington, D.C.; 2009.

9. PERNAMBUCO, SES. PROGRAMA SANAR Cadernos de Monitoramento: Esquistossomose. 1ํe. Recife; 2013.

10. PERNAMBUCO, SES. Guia de apoio operacional ao Sistema de Informação do Programa de Controle da Esquistossomose para os municípios do estado de Pernambuco. Recife; 2012.

11. CAVALCANTI MGS, et al. Morphological characterization of hemocytes from Biomphalaria glabrata and Biomphalaria straminea. Micron. 2012; 43(2-3): 285-91. 
12. ABATH FGC, et al. Molecular approaches for the detection of Schistosoma mansoni: Possible applications in the detection of snail infection, monitoring of transmission sites, and diagnosis of human infection. Mem Inst Oswaldo Cruz. 2006; 101(SUPPL. 1): 145-8.

13. KUNTZ R. Effect of light and temperature on shedding of Schistosoma mansom cercariae. Eff Light Temp shedding [Internet]. 1946; 7: 16.

14. DESLANDES N. Técnicas de dissecção e exame de planorbídeos. Rev do Serviço Espec Saúde Pública. $1951 ; 4$ : 371-82.

15. SOUZA CP de, LIMA LC. Moluscos de interesse parasitologico do Brasil [Internet]. Belo Horizonte: CPqRR; 1990. $76 \mathrm{p}$.

16. BRASIL. Vigilância e Controle de Moluscos de Importância Epidemiológica. Diretrizes Técnicas: Programa de Vigilância e Controle da Esquistossomose (PCE). 2a edição. Brasília: Secretaria de Vigilância em Saúde Departamento de Vigilância Epidemiológica; 2008. 178 p.

17. BAILEY TC, GATRELL AC. Interactive spatial data analysis. 1ำ ed. New York city: Longman Scientific and Technical; 1995. $432 \mathrm{p}$.

18. HARMAN BI, et al. Performance evaluation of IDW, Kriging and multiquadric interpolation methods in producing noise mapping: A case study at the city of Isparta, Turkey. Appl Acoust [Internet]. 2016; 112: 147-57.

19. INSTITUTO BRASILEIRO DE GEOGRAFIA E ESTATÍSTICA - IBGE. Pesquisa nacional de saneamento básico: 2008/IBGE, Coordenação de População e Indicadores Sociais. IBGE, organizador. Rio de Janeiro: Ministério do Planejamento; 2010. $218 \mathrm{p}$.

20. MORGAN JAT, et al. Schistosoma mansoni and Biomphalaria: past history and future trends. Parasitology. 2002; 123(07): 211-28.

21. BARBOSA CS, et al. Current epidemiological status of schistosomiasis in the state of Pernambuco, Brazil. Mem Inst Oswaldo Cruz. 2010; 105(4): 549-54.

22. DIAS LC, et al. Suscetibilidade de Biomphalaria glabrata, B. straminea e B. tenagophila a diferentes cepas de Schistosoma mansoni. Rev Inst Med Trop São Paulo. 1987; 29(4): 205-12.

23. FAVRE TC, et al. A longitudinal study on the natural infection of Biomphalaria straminea and B. glabrata by Schistosoma mansoni in an endemic area of schistosomiasis in Pernambuco, Brazil. Mem Inst Oswaldo Cruz. 2002; 97(4): 465-75.

24. BARBOSA CS, et al. Epidemiologia Da Esquistossomose No Litoral De Pernambuco. Rev Patol Trop [Internet]. $2015 ; 43(4):$ 436-45.

25. YOSHINO TP, et al. Circulating Biomphalaria glabrata hemocyte subpopulations possess shared schistosome glycans and receptors capable of binding larval glycoconjugates. Exp Parasitol. 2013; 133(1): 28-36.

26. Allan $E R O$, et al. Schistosome infectivity in the snail, Biomphalaria glabrata, is partially dependent on the expression of Grctm6, a Guadeloupe Resistance Complex protein. PLoS Negl Trop Dis. 2017; 11(2): e0005362.

27. BARBOSA VS, et al. Modelling of the distribution of Biomphalaria glabrata and Biomphalaria straminea in the metropolitan region of Recife, Pernambuco, Brazil. Geospat Health. 2016; 11(440): 362-7.

28. BARBOSA VS, et al. The Geographic Information System applied to study schistosomiasis in Pernambuco. Rev Saude Publica [Internet]. 2017; 51:107.

29. FACCHINI LA, et al. Assessment of a Brazilian public policy intervention to address schistosomiasis in Pernambuco state: The SANAR program, 2011-2014. BMC Public Health. 2018; 18(1): 1-11. 